\title{
Prevalence of respiratory symptoms associated with outdoor and indoor air pollution in Bogota 2012
}

\author{
R. Sarmiento-Suárez \& K. Medina \\ Surveillance Public Health Area, Bogota Ministry of Health Secretariat, \\ Bogotá, Colombia
}

\begin{abstract}
Bogota is one of the most polluted cities in Latin America, increasing the prevalence of respiratory symptoms in children under five. As the most unequal city in the region, there is a direct gradient between socioeconomic and environmental inequalities. The aim of the study was to know the impact of indoor and outdoor pollution of respiratory disease in children under five in Bogota. A cross sectional study was developed in kindergartens of 15 localities in Bogota, divided into two groups according to exposure level to air pollution. 5407 children under five were selected by two-stage random sampling. A survey instrument based on an ISAAC questionnaire was applied to identify associated factors to respiratory outcomes. Statistical analysis included descriptive $x^{2}$ test and logistic regression by PSPP. Deprived zones of Bogotá were the most affected areas. Wheezing during exercise was associated with outdoor pollution plus unpaved roads $(1.68,1.18-2.38)$; last year wheezing to indoor factors as second hand smoke $(1.82,1.32-1.79)$, dampness $(1.32,1.01-1.74)$ and in-home factory $(1.41,1.02-1.96)$; dry cough at night to second hand smoke $(1.49,1.12$ $1.98)$ and proximity of chimneys $(1.43,1.11-1.86)$. Main predictors for respiratory disease were related to indoor air pollution and social vulnerability, although outdoor pollution was relevant to wheezing during exercise. Second hand smoke is a significant factor in the burden of disease in children under five. Public health policies in Bogotá should address not only outdoor pollution, but also housing inequalities.

Keywords: asthma, respiratory disease, indoor air pollution, outdoor pollution, second hand smoke, dampness, children.
\end{abstract}




\section{Introduction}

Air pollution is one of the factors associated with respiratory disease, in particular in children under five [1]. As a result, high levels of air pollutants as tropospheric ozone, particulate matter (PM) and nitrogen dioxide increase urgent admissions and deaths due to respiratory disease [2-4]. Air pollution affects specific age groups of the population. Indeed, children are especially vulnerable to suffer from a severe respiratory disease because of their anatomic and physiological conditions [5]. What is more, the impact of respiratory disease linked to outdoor air pollution increases school absenteeism [6]. Lower respiratory infections are the main cause of mortality in Colombia for children under five. Moreover, household and ambient particulate matter pollution is ranked as important risk factors of children's premature death and disability in the country [7, 8]. Bogotá is one of the most unequal cities in the world (Gini index=0.61), only surpassed by several South African cities [9]. Since 1990, the inequality gap has increased by $24 \%$ depicting the worst scenario in Latin American cities [9]. Administratively, is divided in 20 zones or localities that in many cases are highly segregated. Such pattern was triggered by a massive influx of people from rural to urban areas, especially due to the internal armed conflict and the collapse of small-scale agriculture after implementation of neoliberal reforms. Currently, Bogotá has become the most densely populated city in Latin America, characterized by peripheral rings of illegal neighbourhoods and rampant informality - around $45 \%$ of the working population are involved in informal jobs [10]. As a consequence, the state of environment has deteriorated seriously during the last decade. According to the World Health Organization (WHO), ambient air quality in Bogotá is the third worst in Latin American cities (annual average level of PM10=77 $\mu \mathrm{g} / \mathrm{m}^{3}$ ) [11]. Most of the particulate matter emissions in Bogotá come from road traffic, but the Air Quality Monitoring Network is not yet measuring black carbon [12]. In fact, combustion engine exhaust fumes are the main source of black carbon, which produces serious health effects on the respiratory system [13]. Thus, the negative impact of road traffic in Bogota is not completely known. However, several studies carried out in Colombia have shown the harmful effects of outdoor air pollution. According to a study developed in Bogota in 1999, an increase of $10 \mu \mathrm{g} / \mathrm{m}^{3}$ might increase the number of urgent admissions due to respiratory disease [14]. Adding up to this, the decreasing trend of pneumonia mortality rate in children under five has stagnated during the last year and plateaued at 10 cases/100.000 inhabitants [15]. Apart from that, we conducted a cohort study between 2007 and 2011 in 3 localities of Bogotá comparing high and low exposed sentinel units through monitoring daily respiratory symptoms and the main findings were: positive association between wheezing and PM10 exposure $(\mathrm{RR}=1.7, \mathrm{CI} 95 \%$ 1.01-1.60) and PM10 and school absenteeism $(\mathrm{RR}=1.70$, CI 95\% 1.26-2.28) as well as the population attributable fraction for particulate matter on wheezing was around $28 \%$ [16]. Such findings are consistent with previous studies that showed an exacerbation of asthma and respiratory disease in direct relation to outdoor pollution [17]. Nevertheless, little 
is known about the effect of indoor pollution from different sources as dampness, second-hand smoke, dust mite or use of solid fuels in Bogotá and its potential interactions with ambient air pollution on the frequency and severity of respiratory disease. As a result of all of this, the aim of the study was to know the prevalence of respiratory disease in children under five living in Bogota and its association to outdoor and indoor air pollution.

\section{Material and methods}

\subsection{Study design}

One hundred and fifty seven public kindergartens in 15 out of 20 localities in Bogotá were selected and further classified according to their level of exposure to outdoor air pollution as high or low exposed sentinel units. The localities included in the study were a representative sample of urban perimeter of Bogota: Usaquén, Santa Fe, Mártires, Candelaria, Tunjuelito, Fontibón, Bosa, Suba, Puente Aranda, Barrios Unidos, Engativá, Ciudad Bolívar, Rafael Uribe, Antonio Nariño and Kennedy. A cross sectional study was designed to evaluate socio demographic, indoor as well as outdoor exposure to air pollution as potential predictors of respiratory disease in children under five in Bogotá.

\subsection{Sampling}

After choosing the sentinel units, a two stage random sampling was carried out to select the population. A sample size of 5,407 children under five was defined from the total population of available data from public kindergartens in Bogotá and then it was proportionally distributed according to the population in each locality and the census of public institutions. Sample size was calculated with the following criteria: (i) prevalence of respiratory disease $20 \%$, (ii) sample error of $3 \%$ and confidence level of $95 \%$. Simple random sampling was applied - once different sample sizes in each institution were identified.

\subsection{Exposure assessment}

Subjective criteria of exposure level included: being close to heavy traffic (less than 100 metres), fixed sources of pollution, economic activities (vehicle repair workshop, incineration activities, recycling warehouses, building material sales, manufacturing, broilers) and non-attainment areas for criteria air pollutants.

\subsection{Instruments}

A survey instrument adapted from the questionnaire of International Study of Asthma and Allergies in Childhood (ISAAC) was applied to parents or caregivers. This survey instrument is validated in Spanish and was approved for being used in Colombia. It consists of 4 groups of questions regarding potential factors associated with respiratory disease: 


\subsubsection{Demographic factors}

It included sex, age, socioeconomic status, health insurance scheme, parents/caregivers education level, and occupation of parents or caregivers. In terms of socioeconomic status, Bogotá is divided into six strata ranging from 1 (lowest sextile) to 6 (highest sextile). In relation to healthcare, Colombia's health insurance system is based on 2 schemes: contributory and subsidised. The rest of the population are not affiliated or belong to special schemes, such as the military forces.

\subsubsection{Medical history}

Several questions were asked regarding history of nutritional problems (low birth weight, nutritional disease), surgical procedures (chest surgery), in utero or early life toxic exposure (smoking, pesticides, heavy metals) and personal and family respiratory diseases (pneumonia, bronchitis, asthma, tuberculosis).

\subsubsection{Occurrence respiratory symptoms}

This set of questions were focused on the outcomes: wheezing at any time in the past, wheezing during the last year, severity of wheezing attacks in the last month, wheezing that limits speech, wheezing during or after exercise, dry cough at night, cough during exercise, school absenteeism due to respiratory symptoms.

\subsubsection{Household outdoor and indoor characteristics}

This part of the questionnaire asked for outdoor home environment, whether or not the child lived in the proximity - less than 100 metres - of potential sources of particulate matter: heavy traffic, unpaved roads/streets or specific economic activities (vehicle repair workshop, incineration activities, recycling warehouses, building material sales, manufacturing, broilers). On the other hand, household indoor characteristics were referred to presence of indoor risk factors for respiratory disease: second hand smoke, inadequate housing, critical overcrowding, bed-sharing, use of solid fuels, types of materials of walls, flooring, dampness and mould, domestic animals, mice or cockroach infestations, in-home factories.

\subsection{Statistical analysis}

Statistical analysis included descriptive, chi square test and logistic regression by SPSS software. Prevalence ratio was used as a measure of association in bivariate analysis and odds ratio was selected as a risk measure for multivariate analysis. Multivariate models were designed for 4 outcomes: wheezing during last year, wheezing during exercise, dry cough at night and school absenteeism, selected by evidence-based information for being the most sensitive to household and ambient air pollution. A descriptive analysis was carried out to obtain the frequency and distribution $\mathrm{n}$ of respiratory symptoms and potential associated factors. Hypothesis testing for bivariate analysis included chi-square or Fischer statistic; null hypothesis were rejected with a significance level $\mathrm{p}$ value $<0.05$. Stratified analysis was done for potential confounders or effect modification using contingency tables through Mantel Hanszel and Breslow Day tests. Co- 
linearity in the 5 groups of variables was checked before modelling multivariate analysis. Four models of logistic regression for specific outcomes (wheezing during last year, dry cough at night, school absenteeism and wheezing during exercise) were built based on significant associations from bivariate and stratified analysis. A logistic regression was run by procedure of likelihood ratio backwards in statistical programs PSPP and Epi Dat 3.

\subsection{Ethical issues}

Parents or caregivers of all participants agreed and signed the informed consent to take part of the study, following Colombia's medical ethics code (Law 23 of 1981) and Ministry of Health regulations (Resolution 8430 of 1993).

\section{Results}

The demographic characteristics of the sample were homogeneous. Age average was 38 months $(\mathrm{SD} \pm 12.9)$ and sex frequencies showed a similar distribution between both sexes $($ Male $=52 \%$, Female $=47 \%$ ). Most of the population belonged to low-middle income class as strata 2 and 3 accounted for $93 \%$. Near $2 / 3$ of the sample was part of the contributory scheme of health insurance $(64 \%)$, whereas only $587(11 \%)$ did not have any insurance scheme. Low quality housing conditions assessment revealed that 650 children lived in inadequate houses $(12 \%)$ and 734 were overcrowded $(13.6 \%)$ as we can observe in table 1 .

Table 1: $\quad$ Socio-demographic factors of participants Bogotá 2012.

\begin{tabular}{|l|l|l|}
\hline \multirow{3}{*}{ Variable } & Categories & n (\%) \\
\hline \multirow{5}{*}{ Sex } & Male & $2854(52 \%)$ \\
\cline { 2 - 3 } & Female & $2553(47 \%)$ \\
\hline \multirow{5}{*}{ Socioeconomic status } & 1 & $329(6 \%)$ \\
\cline { 2 - 3 } & 2 & $2311(42.7 \%)$ \\
\cline { 2 - 3 } & 3 & $2721(50.3 \%)$ \\
\cline { 2 - 3 } & 4 & $37(0.7 \%)$ \\
\cline { 2 - 3 } & 5 & $2(0.03 \%)$ \\
\cline { 2 - 3 } & 6 & $7(0.1 \%)$ \\
\hline Critical overcrowding & & $650(12 \%)$ \\
\hline Health insurance & & $734(13.6 \%)$ \\
& Contributory & $3471(64.2 \%)$ \\
\cline { 2 - 3 } & Subsidised & $1164(21.5 \%)$ \\
\cline { 2 - 3 } & Non affiliated & $185(3.4 \%)$ \\
\cline { 2 - 3 } & Other & \\
\hline Age (months) & Mean: 38 (SD \pm 12.9$)$ & \\
\hline
\end{tabular}


According to the prevalence of respiratory symptoms, the three main events in order of frequency were: whistling at any time in the past (40\%), dry cough at night $(27 \%)$ and wheezing during the last year (19.2\%). Deprived zones of Bogotá were the most affected by respiratory symptoms as Tunjuelito (39\%), Puente Aranda (32\%) and Barrios Unidos (22\%). In regards to severity of attacks, $15 \%$ suffered 1 to 3 attacks in the last month and only $0.9 \%$ had more than 12 attacks. Indeed, severity has not quite high as a low percentage of children in the sample reported having wheezing that limits speech. Such findings are presented in table 2 .

High frequencies of potential associated factors of both indoor and outdoor pollution were observed, as it is shown in table 3 . It is remarkable the prevalence of second hand smoke (25.4\%) and dampness/mould (25\%) as indoor sources of pollution. In addition, there was also high prevalence of people living less than

Table 2: $\quad$ Prevalence of respiratory symptoms Bogotá 2012.

\begin{tabular}{|c|c|}
\hline Respiratory symptom & $\mathrm{n}(\%)$ \\
\hline Whistling at any time in the past & $2204(40.8 \%)$ \\
\hline Wheezing during last year & $1039(19.2 \%)$ \\
\hline Dry cough at night & $1479(27.4 \%)$ \\
\hline Wheezing during exercise & $288(5.3 \%)$ \\
\hline Cough during exercise & $986(18.2 \%)$ \\
\hline School absenteeism & $1257(23.2 \%)$ \\
\hline Attacks of wheezing last month & $4367(80.8 \%)$ \\
None & $813(15.0 \%)$ \\
t to 3 12 & $177(3.3 \%)$ \\
More than 12 & $50(0.9 \%)$ \\
\hline
\end{tabular}

Table 3: $\quad$ Potential associated factors with respiratory disease Bogotá 2012.

\begin{tabular}{|c|c|}
\hline Potential risk factor & $\mathrm{n} \mathrm{( \% )}$ \\
\hline Indoor pollution & \\
\hline Second hand smoke & $1374(25.4 \%)$ \\
\hline Dampness and mould & $1377(25.2 \%)$ \\
\hline In-home factory & $960(17.5 \%)$ \\
\hline Cockroach infestation & $170(3.1 \%)$ \\
\hline Domestic mice & $446(8.2 \%)$ \\
\hline Non clean cooking fuels (carbon/biomass) & $14(0.25 \%)$ \\
\hline Outdoor pollution & \\
\hline High exposure kindergarten & $2829(52.3 \%)$ \\
\hline Living less than 100 m. & $1631(30.2 \%)$ \\
\hline Unpaved roads/streets & $2550(47.2 \%)$ \\
\hline Living less than 100 m. Heavy traffic & $1323(24.2 \%)$ \\
\hline Living less than 100 m chimneys & $549(10 \%)$ \\
\hline Living less than 100 m recycling warehouses & \\
\hline
\end{tabular}


$100 \mathrm{~m}$ of heavy traffic $(47 \%)$, unpaved roads $(30 \%)$ and chimneys $(24 \%)$. On the other hand, the proportion of households that still cooked with solid fuel was very low $(0.25 \%)$ using instead liquefied petroleum gas or electric stoves.

We observed in table 4, that poor quality housing conditions whether linked or not to indoor air pollution was the most statistically significant of all potential factors evaluated for wheezing during the last year and dry cough at night. Dampness and mould was also associated with school absenteeism $(\mathrm{PR}=1.27$, CI 1.15-1.41). Only wheezing during or after exercise has a direct association with high exposure to outdoor pollution in the kindergarten $(\mathrm{PR}=1.11$, CI 95\% $1.00-1.25)$, and was also related to other outdoor sources as unpaved

Table 4: Associated factors with main respiratory symptoms (only significant values).

\begin{tabular}{|l|l|l|l|}
\hline & Yes & No & $\begin{array}{l}\text { Prevalence Ratio } \\
\text { CI 95\%) }\end{array}$ \\
\hline Wheezing during last year & & & \\
\hline Low birth weight & $178(22.7 \%)$ & $851(18.6 \%)$ & $1.20(1.06-1.44)$ \\
\hline Malnutrition history & $144(27.7 \%)$ & $893(18.3 \%)$ & $1.51(1.30-1.75)$ \\
\hline Inadequate housing & $163(25.1 \%)$ & $876(18.4 \%)$ & $1.36(1.17-1.57)$ \\
\hline Critical overcrowding & $168(22.9 \%)$ & $870(18.6 \%)$ & $1.22(1.06-1.42)$ \\
\hline Bed sharing & $534(21.7 \%)$ & $377(18.5 \%)$ & $1.09(1.02-1.16)$ \\
\hline Second hand smoke & $80(31 \%)$ & $228(20.5 \%)$ & $1.52(1.22-1.88)$ \\
\hline Dampness and mould & $345(25.4 \%)$ & $694(17.2 \%)$ & $1.47(1.31-1.65)$ \\
\hline In-home Factory & $208(21.9 \%)$ & $831(18.6 \%)$ & $1.17(1.02-1.34)$ \\
\hline Toxic substances exposure & $156(25.2 \%)$ & $879(18.4 \%)$ & $1.36(1.18-1.58)$ \\
\hline Dry cough at night & & & \\
\hline Second hand smoke & $100(39 \%)$ & $339(30 \%)$ & $1.28(1.07-1.53)$ \\
\hline Inadequate housing & $220(33.9 \%)$ & $\begin{array}{l}1259 \\
(26.5 \%)\end{array}$ & $1.27(1.13-1.43)$ \\
\hline Dampness/mould & $430(31 \%)$ & $1046(26 \%)$ & $1.21(1.10-1.33)$ \\
\hline In-home factory & $296(31 \%)$ & $1183(26 \%)$ & $1.20(1.06-1.35)$ \\
\hline Living less than 100 m. chimneys & $406(31 \%)$ & $1073(26 \%)$ & $1.10(1.08-1.32)$ \\
\hline Wheezing during exercise & & & $1.11(1.00-1.25)$ \\
\hline High exposure outdoor pollution & $166(30.2 \%)$ & $122(25.4 \%)$ & $1.16(1.02-1.30)$ \\
\hline Sex (Male) & $169(31.1 \%)$ & $119(24.5 \%)$ & $1.24(1.02-1.51)$ \\
\hline Second hand smoke & $101(32.7 \%)$ & $187(26 \%)$ & $1.40(1.15-1.70)$ \\
\hline Unpaved roads/streets & $104(35.3 \%)$ & $184(25.1 \%)$ & $1.48(1.24-1.76)$ \\
\hline School absenteeism & & & $1.27(1.15-1.41)$ \\
\hline Dampness/mould & $393(29.3 \%)$ & $858(21.3 \%)$ & $1.36(1.23-1.50)$ \\
\hline Malnutrition history & $161(31 \%)$ & $\begin{array}{l}1092 \\
(22.4 \%)\end{array}$ & $1.48)$ \\
\hline Living less than 100 m chimneys & $364(27.9 \%)$ & $893(21.8 \%)$ & $1.42(1.10-1.70)$ \\
\hline $\begin{array}{l}\text { Living less than 100 m building } \\
\text { material sales }\end{array}$ & $126(30.1 \%)$ & $\begin{array}{l}1131 \\
(22.7 \%)\end{array}$ \\
\hline
\end{tabular}


roads/streets ( $\mathrm{PR}=1.40, \mathrm{CI} 95 \% 1.15-1.70)$. Potential confounding for indoor and outdoor exposure was adjusted for demographic variables (socioeconomic status, sex and age) and also for other factors that were statistically significant in relation to each symptom. Effect modification was observed merely for the outcome wheezing during exercise and the factors unpaved roads and high exposure to outdoor pollution at school (test homogeneity $\mathrm{p}<0.05$ ); for other covariates seemed not to have had an important impact in the outcomes included in the study. After checking for co-linearity we noted inadequate housing was strongly associated with critical overcrowding and low birth weight with malnutrition history $(\mathrm{p}<0.05)$. These results are presented in table 4 .

The main results of multivariate analysis are presented in table 5. After fitting the models for multivariate regression, we obtained data that showed that wheezing during last year was positively associated with age $(\beta=0.034, p<0.05)$, low birth weight $(\beta=0.678, p<0.05)$, second-hand smoke $(\beta=0.599, p<0.05)$,

Table 5: Multivariate analysis. Logistic regression respiratory symptoms Bogotá 2012.

\begin{tabular}{|l|c|c|c|}
\hline & Beta coefficient & p value & OR (CI 95\%) \\
\hline $\begin{array}{l}\text { Model 1. Wheezing during } \\
\text { last year }\end{array}$ & & & \\
\hline Age & 0.034 & 0.000 & $1.03(1.02-1.04)$ \\
\hline Low birth weight & 0.678 & 0.000 & $1.96(1.40-2.75)$ \\
\hline Second hand smoke & 0.599 & 0.000 & $1.82(1.32-1.89)$ \\
\hline Dampness and mould & 0.282 & 0.045 & $1.32(1.01-1.74)$ \\
\hline In-home factory & 0.35 & 0.034 & $1.41(1.02-1.96)$ \\
\hline Model 2. Dry cough at night & & & \\
\hline Age & 0.009 & 0.041 & $1.00(1.00-1.01)$ \\
\hline Inadequate housing & 0.35 & 0.026 & $1.42(1.04-1.94)$ \\
\hline Second hand smoke & 0.399 & 0.006 & $1.49(1.12-1.98)$ \\
\hline $\begin{array}{l}\text { Living less than 100 m. } \\
\text { chimneys }\end{array}$ & 0.360 & 0.006 & $1.43(1.11-1.86)$ \\
\hline $\begin{array}{l}\text { Model 3. Wheezing during } \\
\text { exercise }\end{array}$ & & & \\
\hline Age & 0.011 & 0.042 & $1.01(1.00-1.02)$ \\
\hline Sex (Male) & 0.325 & 0.022 & $1.38(1.04-1.82)$ \\
\hline Second hand smoke & 0.350 & 0.019 & $1.42(1.05-1.90)$ \\
\hline $\begin{array}{l}\text { Unpaved roads*high exposure } \\
\text { to outdoor pollution }\end{array}$ & 0.520 & 0.004 & $1.68(1.18-2.38)$ \\
\hline Model 4. School absenteeism & 0.011 & 0.000 & $1.01(1.00-1.01)$ \\
\hline Age & 0.42 & 0.000 & $1.52(1.24-1.86)$ \\
\hline Malnutrition & 0.39 & 0.000 & $1.40(1.28-1.70)$ \\
\hline Dampness and mould & 0.30 & 0.000 & $1.36(1.17-1.57)$ \\
\hline $\begin{array}{l}\text { Living less than 100m } \\
\text { chimneys }\end{array}$ & 0.30 & 0.008 & $1.35(1.08-1.59)$ \\
\hline $\begin{array}{l}\text { Living less than 100m building } \\
\text { materials sales }\end{array}$ & & & \\
\hline
\end{tabular}


dampness/mould $(\beta=0.282, \mathrm{p}<0.05)$ and in-home factory $((\beta=0.35, \mathrm{p}<0.05)$. Toxic substances exposure was no longer significant after adjusting in logistic regression model for wheezing during last year and the same happened with bed sharing. On the other hand, for dry cough at night we found an association with age $(\beta=0.009, \mathrm{p}<0.05)$, inadequate housing $(\beta=0.35, \mathrm{p}<0.05)$, second hand smoke $(\beta=0.399, p<0.05)$ and children living near chimneys $(\beta=0.360, p<0.05)$. The only outcome that needed to create an interaction term in the model was wheezing during exercise with high exposure criteria and unpaved roads $(\beta=0.520, p<0.05)$. Moreover, being male $(\beta=0.325, p<0.05)$, second-hand smoke $(\beta=0.350, \mathrm{p}<0.05)$ and age $(\beta=0.011, \mathrm{p}<0.05)$ had a positive association with this event. Respiratory disease-related school absenteeism had an association with age $(\beta=0.011, \mathrm{p}<0.05)$, malnutrition history $(\beta=0.42, \mathrm{p}<0.05)$, dampness/mould $(\beta=0.39, \mathrm{p}<0.05)$ and living near building material sales $(\beta=0.30, \mathrm{p}<0.05)$ or chimneys $(\beta=0.30, \mathrm{p}<0.05)$.

\section{Discussion}

According to previous studies we did not observe the significant impact of outdoor pollution on respiratory symptoms in the children attending public kindergartens. Only wheezing during physical activity was associated with outdoor pollution. Furthermore, there is a multiplying effect on wheezing during exercise accounted for people living in the proximity of unpaved roads or street and that attended high exposure kindergarten ( $\mathrm{OR}=1.68$, CI 95\% $1.18-2.38)$. Such findings have already been described in the literature [18]. This study showed a consistent and strong relation between indoor pollution and an increased prevalence of respiratory symptoms, especially with factors as second hand smoke and dampness and mould. In our study, second hand smoke was a positive predictor of wheezing during the last year $(\mathrm{OR}=1.82$, CI 95\% 1.32$1.89)$, dry cough at night $(\mathrm{OR}=1.49,1.12-1.98)$ and wheezing during exercise $(\mathrm{OR}=1.42$, CI 95\% 1.05-1.90). By 2004, second-hand smoke exposure caused 603.000 premature deaths in the world. Among them, 166000 children died from lower respiratory infections and 1100 died from asthma. About $28 \%$ of deaths attributable to second hand smoke happened in children [19]. In Bogotá is not known the burden of disease in children from passive smoking, but the high prevalence of second-hand smoke $(25 \%)$ is preoccupying. Although Colombia signed the Framework Convention on Tobacco Control, the taxes on smoking are very low in the country and it is well known that health expenditure associated with smoking is four times more than collection of taxes from tobacco industry [20]. Smoking consumption is very sensitive to price elasticity as low-income populations reduce consumption with tax policies. As a result, it is needed even more strict tax policies on tobacco industry to overcome such negative health impacts [21-23]. Moreover, strategies as smoke free homes supported by regulations and contraventions in some places seemed to be having a positive impact on reducing passive smoking [24]. In addition, we found that dampness/ mould was associated to wheezing during last year $(\mathrm{OR}=1.32$, CI 95\% 1.01$1.74)$ and school absenteeism $(\mathrm{OR}=1.40, \mathrm{CI} 95 \% 1.28-1.70)$. It depends on the 
growth of fungi and bacteria when there is enough moisture. These findings have also been described in several studies carried out in other countries, probably linked to lack of ventilation of the indoor environment. Some researchers have suggest that remediation of dampness might reduce respiratory symptoms [25]. We also found an association between respiratory symptoms and presence of inhome factories. Previous studies have described a prevalence of $13 \%$, but we observed a prevalence of $17.5 \%$ [14]. As we discussed before, the fact that nearly $50 \%$ of the people work and live in informal conditions, forced them to run their own business inside their households with subsequent events of ill health, principally related to emission of pollutants. Therefore, it is a kind of regressive industrial system that can also be seen in informal transportation system, highly pollutant due to lack of maintenance or use of non-clean fossil fuels. Finally, we observed residual exposure in the outdoor home environment expressed as heavy traffic, building material sales and unpaved roads and streets that affect also children respiratory health. This study has some limitations as the methodological design would not have taken into account other potential confounders for respiratory disease as meteorological conditions, pollen or dust mite. Also multilevel analysis would be preferable in environmental exposure. Even more, criteria used for classifying the high and low exposure sentinel units were subjective so that could have been misclassification that explained no significant association for many of the respiratory symptoms assessed. Further research should incorporate methods for assessing cumulative impacts [26]. Most important predictors for respiratory disease in this study were related to indoor air pollution and social vulnerability, although outdoor pollution was relevant to some symptoms as wheezing during exercise. As a result, the direct gradient between socioeconomic and environmental inequalities highlights the need that public health policies in Bogotá should address not only outdoor pollution, but also housing and socioeconomic inequalities.

\section{References}

[1] Gauderman, WJ. Air pollution and children - an unhealthy mix. $N$ Eng $J$ Med 2006, 355:78-9.

[2] Gouveia, N; Freitas CU; Martins LC; Marcilio, IO. Respiratory and cardiovascular hospitalizations associated with air pollution in the city of São Paulo, Brazil. Cadernos de Saude Publica. 2006, 114 (4):532-536.

[3] Dales, RE; Cakmak, S; Doiron MS. Gaseous pollutants and hospitalization for respiratory disease in the neonatal period. Environ Health Perpect. 2006, 114 (11): 1751-1754.

[4] Pope, CA; Dockery, DW; Spengler, JD; Raizenne, ME. Respiratory health and PM 10 pollution: a daily time series analysis. Am Rev Resp Dis. 1991, 144 (3): 668-674.

[5] Ward, D; Ayres I. Particulate air pollution and panel studies in children: a systematic review. Occup Environ Med. 2004, 61:1-12. 
[6] Gilliland, F; Berhane, K; Rappaport, EB The effects of ambient air pollution on school absenteeism due to respiratory illness. Epidemiology 2001, 12: 43-54.

[7] Institute of Health Metrics and evaluation, Global burden of disease 2012. Available at: http://www.healthmetricsandevaluation.org/gbd/ visualizations/gbd-heatmap. Accessed April 10, 2013.

[8] Vos, T; Flaxman, A; Naghavi, M; Lozano, R et al. Years lived with disability (YLDs) for 1160 sequelae of 289 diseases and injuries 19902010: a systematic analysis for the Global Burden of Disease Study 2010, Lancet 2012, 380: 2163-96.

[9] United Nations Habitat. State of the world's cities 2010- 2011: bridging the urban divide 2012. Available at http://www.unhabitat.org/pmss /listItemDetails.aspx?publicationID=2917, Accessed March 17, 2013.

[10] Departamento Administrativo Nacional de Estadística (DANE), Resumen ejecutivo Medición del empleo informal available at: https://www.dane.gov.co/daneweb_V09/files/investigaciones/boletines/ec h/ech_informalidad/re_ech_informalidad_dic_feb2012.pdf. Accessed April 1, 2013.

[11] World Health Organization (WHO). Outdoor pollution database in cities. Available at: http://www.who.int/phe/health_topics/outdoorair/databases /en/. Accessed November 26, 2012.

[12] Secretaría Distrital de Ambiente, Atlas Ambiental de Bogotá 2007, available at: http://oab.ambientebogota.gov.co/resultado_busquedas.php? AA_SL_Session $=8 \mathrm{cf} 97 \mathrm{c} 692 \mathrm{~b} \& \mathrm{x}=3947$. Accessed 7 June, 2012.

[13] Smith, K; Jerret, M; Anderson, RH et al. Public health benefits of strategies to reduce greenhouse gas emissions: health implications of short-lived pollutants. Lancet 2009, 74:2091-2103.

[14] Solarte, I; Caicedo, M; Restrepo, S. Contaminación atmosférica y enfermedad respiratoria en menores de 14 años en Bogotá, Revista Médica Sanitas, Vol. 5 N2.

[15] Secretaría Distrital de Ambiente, Observatorio Ambiental de Bogotá, available at: http://oab.ambientebogota.gov.co/index.shtml?s=1\&id=532\& $\mathrm{v}=1$. Accessed April 3, 2013.

[16] Hernández, L; Aristizábal, G, Medina, K; Quiroz, L; Sarmiento-Suárez, R. Relación entre la contaminación intra y extramural y enfermedad respiratoria en menores de 5 años en Bogotá, Colombia, 2007-2010, Informe al Concejo de Bogotá, 2012, Pgs. 82.

[17] Rabinovitch N, Strand M, Gelfand EW. 2006. Particulate levels are associated with early asthma worsening in children with persistent disease. Am J Respir Crit Care Med 173:1098-1105.

[18] McCormack, M; Breysee, P; Matsui, E; Hansel, N; Williams, D; CurtinBrosnan, J; Eggleston, P; Diette, G. In-home particle concentrations and childhood asthma morbidity Environ Health Perspect 2009; 117(2): 294298.

[19] Öberg, M, Woodward A, Jaakkola,M, Peruga A, Prüss Ustün, A Global estimate of the burden of disease from second hand smoke, World Health 
Organization 2010, available http://whqlibdoc.who.int/publications /2010/9789241564076_eng.pdf

[20] Muller, F; Wehbe, L. Smoking and smoking cessation in Latin America: a review of the current situation and available treatments. Int J COPD 2008; 3(2): 285-293.

[21] Chaloupka FJ. Contextual factors and youth tobacco use: policy linkages. Addiction 2003; 98 Suppl 1: 147-149.

[22] Jha P, Chaloupka FJ, et al. Reducing the burden of smoking world-wide: effectiveness of interventions and their coverage. Drug Alcohol Rev 2006; 25(6): 597-609.

[23] Thomas S, Fayter D., Misso K., et al. Population tobacco control interventions and their effects on social inequalities in smoking: systematic review. Tobacco Control 2008; 17: 230-237. doi:10.1136/ tc.2007.023911 Downloaded from tobaccocontrol.bmj.com on December $16,2011$.

[24] Thomson G, Wilson N, et al. Population level policy options for increasing the prevalence of smokefree homes. J Epidemiol Community Health 2006; 60(4): 298-304.

[25] World Health Organization (WHO). WHO Guidelines for Indoor Air Quality: Dampness and mould. 2009. Available at http://www.euro.who.int/_data/assets/pdf_file/0017/43325/E92645.pdf

[26] Alexeef, G; Faust J; August L M; Milanes, C; Randles, K; Zeise, L; Denton, J. A screening method for assessing cumulative impacts Int $J$ Environ Res Public Health 2012; 9: 648-659; doi:10.3390//ijerph9020648 